\title{
Chronic Hypoxia and Rat Lung Development: Analysis by Morphometry and Directed Microarray
}

\author{
WILLIAM E. TRUOG, DONG XU, IKECHUKWU I. EKEKEZIE, SHERRY MABRY, MO REZAIEKHALIGH, \\ STAN SVOJANOVSKY, AND MICHAEL J. SOARES
}

\begin{abstract}
Department of Pediatrics [W.E.T., D.X., I.I.E., S.M., M.R.], Section of Neonatology, University of Missouri-Kansas City School of Medicine, Children's Mercy Hospitals and Clinics, Kansas City, Missouri 64108; Department of Pathology and Laboratory Medicine [M.J.S.], Institute of Maternal-Fetal Biology [W.E.T., M.J.S.], Department of Molecular and Integrative Physiology [S.S.], University of Kansas School of Medicine, Kansas City, Kansas 66160
\end{abstract}

\begin{abstract}
It is unclear how sublethal hypoxia affects lung development. To investigate the effects of chronic hypoxia on postnatal lung remodeling, we treated neonatal rats with $\mathrm{FIO}_{2}$ of 0.12 for $10 \mathrm{~d}$ and analyzed lung development by morphometry and gene expression by DNA microarray. Our results showed the neonatal rats exposed to hypoxia reduced body weight by $42 \%$ and wet lung weight by $32 \%$ compared with the neonatal rats exposed to normoxia. In the neonatal rats exposed to hypoxia, the radial alveolar counts were decreased to 5.6 from 7.9 and the mean linear intercepts were increased to $56.5 \mu \mathrm{m}$ from $38.2 \mu \mathrm{m}$. In DNA microarray analysis, approximately half of probed genes were unknown. Chronic hypoxia significantly regulated expression of genes that are involved in pathogenesis of pulmonary hypertension and postnatal lung remodeling. Chemokine ligand 12, jagged 2 were among those upregulated; c-kit, ephrin A1, and Hif- $2 \alpha$ were among those downregulated. The altered expression of those genes was correlated with the lung development and remodeling. (Pediatr Res 64: 56-62, 2008)
\end{abstract}

$\mathrm{D}^{\mathrm{e}}$ evelopment of the immature lung with a saccular morphology and limited gas exchange area to an architecturally mature lung with large internal surface area takes many steps: thinning of alveolar septal walls, concomitant growth of the capillary network, and extensive subdivision of gas exchange or acinar units. Alveolar septation apparently occurs as secondary crests extend from primary alveolar walls and the alveolar capillary network becomes more complex $(1,2)$. Vascular development occurs by means of vasculogenesis, the development of blood vessels from the differentiating of angioblasts in the mesoderm, and the more clinically relevant process of angiogenesis, the sprouting of blood vessels from existing vessels. Preacinar pulmonary arteries supplied by the right heart grow with the airways into the intraacinar region infused with the peripheral microvasculature that has arisen there by means of vasculogenesis (3). Angiogenesis is orchestrated and mediated by interaction between and among protein ligands and their cognate receptors to induce endothelial cell proliferation, migration, differentiation, and organization as

Received September 25, 2007; accepted February 6, 2008

Correspondence: William E. Truog, M.D., Department of Pediatrics, Section of Neonatology, Children's Mercy Hospitals and Clinics, 2401 Gillham Road, Kansas City, MO 64108; e-mail: wtruog@cmh.edu

This study was supported in part by the Hall Family Foundation, Kansas City, Missouri for advancement of pediatric research and in part by the K-INBRE Bioinformatics Core, in part by NIH P20 RR016475 and in part by R-01HL70560 (W.E.T.). well as remodeling into vascular networks $(4,5)$. The requirement of normal pulmonary vascularization for alveolarization implies an interrelationship between capillary invasion and alveolar septation (6). Factors that interfere with this process may be sublethal in nature but result in long-term pulmonary functional limitations (7).

Pulmonary vascular development proceeds under hypoxic conditions in the fetus. Hypoxia is known to modulate the expression of angiogenic factors and potentially to affect lung microvascular development and lung morphogenesis (8). However, the impact on microvascular alterations at the level of these angiogenic factors by changes in oxygen tension has not been thoroughly studied.

There are clinical implications to this issue. In the clinical disorder, bronchopulmonary dysplasia (BPD), regional alveolar hypoxia likely develops in association with the distal airway heterogeneous changes previously described (9). Maldistribution of ventilation may develop especially during the early phases of BPD when either no increase or when only modest increases in $\mathrm{FIO}_{2}$ are administered. Alveolar hypoxia then would develop in areas with very low ventilationperfusion ratios. Separate from the postnatal problems arising in BPD, sustained altitude associated hypoxia has been associated with reduced gas exchange efficiency in otherwise healthy term infants (10).

To evaluate the effects of alveolar hypoxia on developing lung, we used the rat pup, whose saccular and alveolar stages of development occur postnatally during the first $2 \mathrm{wks}$, compared with prenatally in humans (2). We sought to relate morphometric findings of microvascular and septal development to alterations in lung expression of vasoactive substances.

\section{METHODS}

Animal exposure to oxygen. All experiments were conducted by protocols
approved by the Institutional Animal Care and Use Committee at the Uni-
versity of Kansas School of Medicine. Three treatment groups of pups were
created: pups from dams fed ad libitum and maintained in normoxia (room air,
$n=11)$, pups exposed to hypoxia $\left(\mathrm{FIO}_{2}=0.12\right)$ from day 4 to day 14 of life
$(n=11)$, whose dams were fed ad libitum; and pups maintained in normoxia,
whose dams were pair-fed based on the amount of food consumed by their

Abbreviations: BPD, bronchopulmonary dysplasia; Lm, mean linear intercept; RAC, radial alveolar count; TLR, toll-like receptor 
hypoxia-exposed counterparts $(n=11)$. Normoxia and hypoxia dams in these groups were rotated every $24 \mathrm{~h}$ during hypoxia exposure.

Total RNA preparation from tissue. Pups killed on day 10 of exposure (14 $\mathrm{d}$ of life) had lung tissue harvested. Total RNA was extracted with TRIzol reagent from Invitrogen according to the manufacturer's protocol. One microgram of total RNA was used for the first strand cDNA synthesis using oligo $\mathrm{d}(\mathrm{T})$ primers according to the first strand cDNA synthesis kit protocol from Invitrogen. Before cDNA synthesis, total RNA was treated with RNase-free DNase I to eliminate any DNA contamination; nonreverse-transcription (without adding reverse transcriptase in cDNA synthesis) samples were also included as negative controls. The resulting cDNAs were then used for real-time PCR. The primers used for Jagged 2 were, sense $5^{\prime}$-TGCACTGGTAGAGTACGTCCTTGT-3' and antisense, 5'-AACAA CCAGTGGGCTCCGCTCAAT-3'; for CXCL12: sense, 5'-GCCAACGTCAAACATCTGAA-3', antisense: 5'TAATTTCGGGTCAATGCACA-3'. The real-time PCR was run with SYBR green using two-step PCR protocol $\left(95^{\circ} \mathrm{C}\right.$ for $3 \mathrm{~min} ; 95^{\circ} \mathrm{C}$ for $10 \mathrm{~s}$, and $55^{\circ} \mathrm{C}, 45 \mathrm{~s}$ for 40 cycles) with melting curve. The threshold cycle (Ct) was used to quantify the sample mRNA levels with housekeeping gene $\beta$-actin normalization.

Immunohistochemistry. Pups were killed at exposure day 0 (baseline) and exposure days 3 and 10. Lungs were tracheally-perfused and fixed at $24 \mathrm{~cm}$ $\mathrm{H}_{2} \mathrm{O}$ pressure for $24 \mathrm{~h}$, with $4 \%$ buffered formaldehyde solution for histologic studies. The lungs were then processed for histology by cutting into blocks at right angles to the main bronchus. Tissue blocks were embedded in paraffin and sectioned at a thickness of $5 \mu \mathrm{m}$. Samples were mounted on positively charged glass microscope slides and kept in a $60^{\circ} \mathrm{C}$ oven overnight, then deparaffinized, and rehydrated. Staining was enhanced by steaming slides in target retrieval solution (DAKO, Carpinteria, CA) for $20 \mathrm{~min}$. After incubation with blocking serum (DAKO, Carpinteria, CA) for $10 \mathrm{~min}$, slides were incubated with mouse anti-rat monoclonal PECAM-1 (CD31) antibody for $1 \mathrm{~h}$ (Serotec, Kidlington, Oxford, UK). Sections were then immunohistochemically stained using a modified avidin-biotin-peroxidase method (Vectastain ABC Elite Kit, Vector Laboratories, Burlingame, CA). Antigenic sites were visualized by addition of the chromogen 3,3' diaminobenzidine. Slides were counterstained with Harris hematoxylin (Fisher HealthCare, Houston, TX). Negative control slides were stained using the same procedure, omitting the primary antibody.

Western blotting analysis. Antibodies were purchased from Santa Cruz, $\mathrm{CA}$ and used according to manufacturer's instructions. Lungs were homogenized in RIPA buffer containing PBS, 0.1\% SDS, 1\% Igepal CA-630 (Sigma Chemical Co., St. Louis, MO), and $0.5 \%$ sodium deoxycholate. At the time of use, the following inhibitors were used in per gram tissue: $100 \mu \mathrm{g} / \mathrm{mL}$ PMSF, $30 \mu \mathrm{M}$ Aprotinin (Sigma Chemical Co., St. Louis, MO), and $1 \mathrm{mM}$ sodium orthovanadate. The homogenate was centrifuged at $15,000 \mathrm{~g}$ at $4^{\circ} \mathrm{C}$ for $20 \mathrm{~min}$. Protein was measured using bicinchoninic acid protein assay kit (Sigma Chemical Co., St. Louis, MO) and then $60 \mu \mathrm{g}$ of protein/lane was applied on a $10 \%$ Bis-Tris gel (Invitrogen, Carlsbad, CA). Protein was transferred to a nitrocellulose membrane. The membrane was incubated for one hour at room temperature with $5 \%$ nonfat milk in PBST $(0.1 \%$ Tween-20 in PBS) to block nonspecific binding. The membrane was immunoblotted with the primary antibody at $4{ }^{\circ} \mathrm{C}$ overnight, followed by three 5-min washes with PBST and then incubated with horseradish peroxidase-conjugated secondary antibody. Detection was conducted by an enhanced chemiluminescent technique (Santa Cruz, CA). The signals on autoradiogram were analyzed with Image software (Alpha Innotech, Sunnyvale, CA) and normalized by $\beta$-actin in the same sample.

Morphometric analysis. Radial alveolar counts (RAC) were measured as previously described $(11,12)$, from the center of a bronchiole lined by epithelium in one part of the wall. A perpendicular line was drawn using image analysis to the nearest connective tissue septum or lung pleural surface, and the number of alveoli cut by the line was counted. The radial alveolar count was measured for every bronchiole on a slide and an average radial alveolar count for the slide was calculated. All analyses were performed without knowledge of the exposure group.

Mean linear intercepts $(\mathrm{Lm})$ were measured using crossed hairlines of known length (13). Fourteen consecutive parenchymal fields from each lung were examined at $\times 200$ magnification, on 5- $\mu \mathrm{m}$ sections from the left lower lobe.

Using ANALYSIS Image Analysis (Soft Imaging Software, Lakewood, CO), the volume density of PECAM-1 stained tissue $\left(\mathrm{V}_{\mathrm{V} \text { PECAM }}\right)$ per parenchyma was determined in 14-d-old (day 10 of treatment) rat lungs. Parenchyma was defined as alveolar ducts, alveoli, saccules, their air spaces, and septa. Fifteen fields per animal were measured and averaged to obtain $\mathrm{V}_{\mathrm{V} \text { PECAM }}$.

DNA microarray analysis. Experimental design of the microarray analysis consists of three technical replicates for control and three replicates for the hypoxia group. We used Affymetrix Rat 230 v.2.0 high density GeneChip ${ }^{\circledR}$ and scanned with a GeneChip ${ }^{\circledR} 3000$ High-resolution Scanner (Affymetrix, Santa Clara, CA). This array represents about 31,000 probe sets for gene expression level analysis of over 30,000 transcripts and variants that correspond to over 28,000 well-substantiated rat genes. The initial data captured by Affymetrix GeneChip Operating Software (GCOS) resulted in a single raw value related to each probe set based on the mean of differences between the intensity of hybridization for each perfect match and the mismatch features for a specific transcript. Experimental data set was exported via Data Transfer Tool into the library data file by the GCOS software. Data Mining Tool components were used to process the initial data quality control assessment and to create sets of expressed probes. Total set of 31,099 probes for this particular rat genome was divided into "present," "marginal," and "absent" subsets based on calculated probe detection $p$-value. Probes present in at least two microarray chips out of three in treatment $v s$. control were used for evaluation of upregulated genes, whereas for downregulated genes probes present in two of three control arrays facilitated the base for comparison. Signal intensities for individual probe sets in the treatment and control triplicates were subsequently compared statistically with significant differences at $p \leq 0.05$. GeneChip data sets from GCOS were transferred into text file inputs for GeneSpring software (Agilent Technologies, Silicon Genetics, Redwood City, CA), normalized per chip and gene and ranked according to fold change for treatment $v s$. control signal intensities. GeneSpring software was also used for graphical interpretation, gene annotation and gene ontologies for biologic processes, molecular functions, and cellular components.

Statistical analysis. The results are expressed as the mean \pm SEM of data obtained from two or more experiments; or where appropriate, as mean $\pm \mathrm{SD}$. Paired or unpaired t tests were used as appropriate for the continuous data. A value of $p<0.05$ was considered significant.

\section{RESULTS}

Chronic hypoxia exposure lowers the body weight and lung wet weight of the newborn rats. Newborn rats exposed to hypoxia $\left(\mathrm{FIO}_{2}\right.$ of 0.12$)$ from days 4 to 14 showed a significant body and lung wet weight reduction. During 10-d treatment, body weight of the newborn rats breathing $12 \%$ oxygen decreased to $15.7 \mathrm{~g}, 42 \%$ reduction, compared with that of the newborn rats breathing room air (normoxia) with either $a d$ libitum $(27 \mathrm{~g})$ or limited fed $(24 \mathrm{~g})(n=11, p<0.002)$. The lung wet weight of the newborn rats breathing $12 \%$ oxygen declined to $0.28 \mathrm{~g}, 32 \%$ reduction, compared with that of the newborn rats breathing room air (normoxia) with ad libitum $(0.41 \mathrm{~g})$ or limited fed ( $0.41 \mathrm{~g})$ (Table $1 ; n=11, p<0.001)$. Lung weight to body weight ratios for each group are shown and demonstrate that hypoxic exposure reduced overall body weight proportional to lung weight (Table 1).

Chronic hypoxia exposure impairs alveolar formation of the newborn rats. The newborn rats exposed to 10-d hypoxia showed a significant RAC reduction. It was decreased to 5.6 from 7.9 or 7.8 compared with the newborn rats exposed to normoxia with ad libitum or limited fed (Table 2; $n=11, p<$ 0.002). The $\mathrm{Lm}$ was increased in the neonatal rats exposed to hypoxia compared with the neonatal rats exposed to normoxia. $\mathrm{Lm}$ was significantly increased to $56.5 \mu \mathrm{m}$ from $38.2 \mu \mathrm{m}$ after 10-d hypoxia exposure (Fig. 1; $p<0.05, n=3-4$ ). No changes were found after $3 \mathrm{~d}$ exposure to hypoxia. Lung histology analyses showed a homogenous alveolar formation

Table 1. Chronic hypoxic exposure lowers the body weight and lung wet weight of the newborn rats

\begin{tabular}{lccc}
\hline & $\begin{array}{c}\text { Body weight } \\
(\mathrm{g}), n=11\end{array}$ & $\begin{array}{c}\text { Wet lung weight } \\
(\mathrm{g}), n=7\end{array}$ & $\begin{array}{c}\text { Lung } \\
\text { weight/body } \\
\text { weight, } n=\end{array}$ \\
\hline Normoxia (ad libitum) & $27 \pm 2$ & $0.41 \pm 04$ & $0.015 \pm 0.002$ \\
Normoxia (limited fed) & $24 \pm 2$ & $0.41 \pm 04$ & $0.017 \pm 0.003$ \\
Hypoxia & $15.7 \pm 2^{*}$ & $0.28 \pm 03^{*}$ & $0.016 \pm 0.032$ \\
\hline
\end{tabular}

The body weight, lung wet weight, and lung weight to body weight ratio of the neonatal rats were assessed after 10-d exposure to normoxia $\left(21 \% \mathrm{O}_{2}\right)$ or hypoxia $\left(12 \% \mathrm{O}_{2}\right)$.

$* p<0.001$ compared with normoxia groups. 
Table 2. Chronic hypoxic exposure impairs alveolar formation of the newborn rats

\begin{tabular}{lc}
\hline & $\begin{array}{c}\text { Radial alveolar } \\
\text { count (RAC) }\end{array}$ \\
\hline Normoxia (ad libitum) & $7.9 \pm 1.0$ \\
Normoxia (limited fed) & $7.8 \pm 0.9$ \\
Hypoxia & $5.6 \pm 1.3^{*}$ \\
\hline
\end{tabular}

The radial alveolar count (RAC) was measured in the neonatal rat lungs after 10-d exposure to normoxia $\left(21 \% \mathrm{O}_{2}\right)$ or hypoxia $\left(12 \% \mathrm{O}_{2}\right)$.

$* p<0.02$ compared with normoxia groups.

in the newborn rats treated with normoxia with ad libitum or limited fed (Fig. 2A). However, the alveolar formation was reduced in the newborn rats treated with hypoxia and there were fewer and larger alveoli in the hypoxia-treated lungs compared with normoxia-treated lungs (Fig. 2B).

Chronic hypoxia exposure impairs pulmonary vascularization of the newborn rats. Pups exposed to 10-d hypoxia showed a significant PECAM staining reduction. It was significantly decreased to $2.3 \%$ from $4.4 \%$ compared with the newborn rats exposed to normoxia with ad libitum (Fig. 3; $n=$ $2-4, p<0.005)$

Chronic hypoxia exposure alters gene expression in the newborn rat lungs. Upregulated genes after chronic hypoxia in the newborn rat lungs are summarized in Table 3 and downregulated genes are summarized in Table 4. They represent only significantly upregulated or downregulated genes $(\mathrm{t}$ test $p$-value $<0.005$ ) with the fold change exceeding 2.0. Because we have three technical replicates for each, treatment, and control, the fold change was calculated from the average

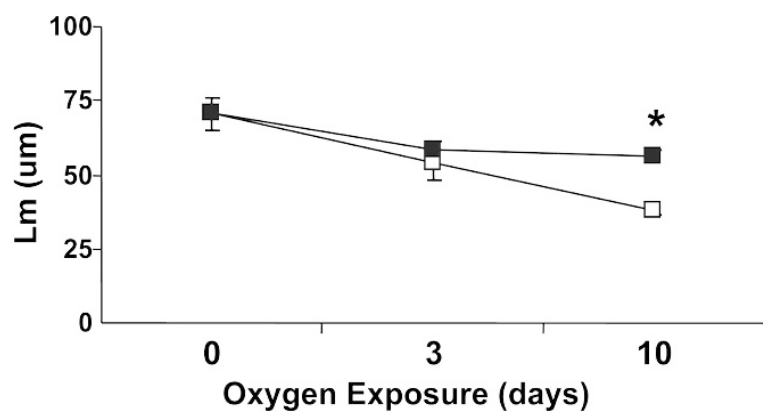

Figure 1. Quantitative analysis of alveolar formation by the mean linear intercept (Lm) measurement. Tissue sections from fixed neonatal rat lungs exposed to either normoxia or hypoxia were measured for the mean linear intercept under light microscope. Open squares: normoxia; closed squares: hypoxia. ${ }^{*} p<0.05$ compared with 10 -d normoxia treatment group.

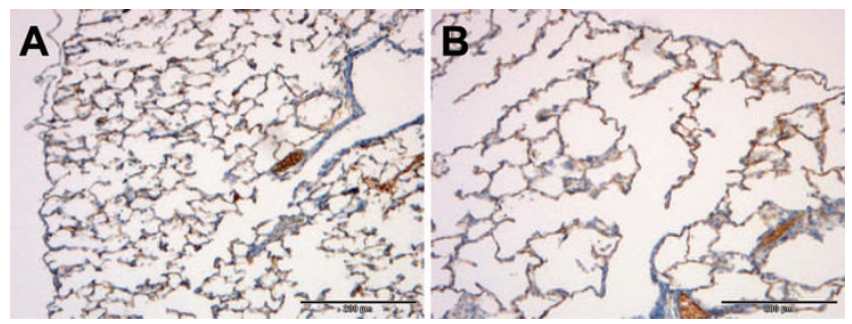

Figure 2. Chronic hypoxia exposure alters pulmonary morphology of the newborn rats. Five micrometer sections from the neonatal rat lung tissues were stained with hematoxylin and eosin $(\mathrm{HE}, 100 \times)$. (A) A representative lung section from normoxic group; $(B)$ a representative lung section from hypoxic group.

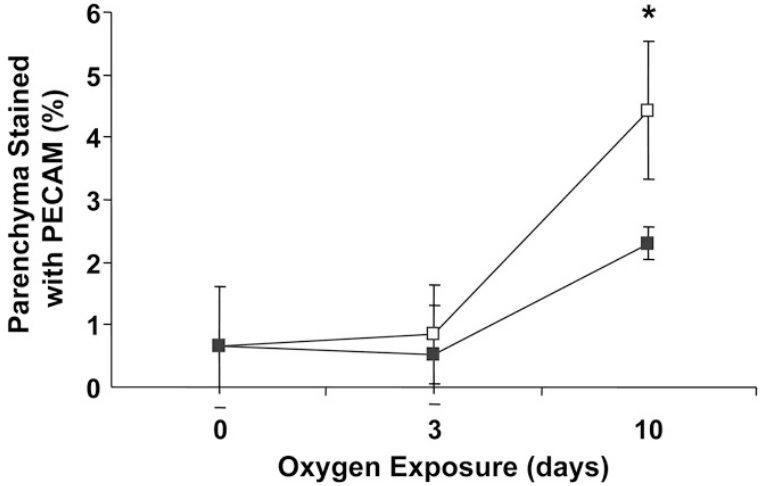

Figure 3. Chronic hypoxia exposure impairs pulmonary vascularization of the newborn rats. Lung tissue slides from the neonatal rats exposed to normoxia or hyperoxia were staining with PECAM-1 and the staining signals were quantified by ImageAnalysis software. Open squares: normoxia; closed squares: hypoxia. ${ }^{*} p<0.005$ compared with 10 -d normoxia treatment group.

signals for treatment and control. Our selection is only on genes present (detection $p$-value $<0.05$ ) in at least two of the three replicates. The genes are then clustered in different subgroups based the gene annotation and gene ontology. Among those significantly differentially expressed genes, approximately half of those genes were unknown. Chronic hypoxia exposure of the neonatal rat lungs significantly upregulated 66 genes with known functions (Table 3). These genes participate in biologic process and molecular function in almost every cellular compartment. Neurotrophic tyrosine kinase, receptor, type 2, chemokine (C-X-C motif) ligand 12, jagged 2 and peroxiredoxin 2 were among those upregulated. The upregulation of those genes suggested that chronic hypoxia increased cellular metabolism, induced inflammation, reduced antioxidant capacity, and interrupted lung development.

The 56 downregulated genes with known functions were likely involved in pathogenesis of pulmonary hypertension, angiogenesis, and changes in extracellular matrix (Table 4). c-kit receptor tyrosine kinase, aldehyde dehydrogenase family 1, phosphatidylinositol 3-kinase, catalytic, alpha polypeptide, ephrin A1, and endothelial PAS domain protein 1 (Hif- $2 \alpha$ ) were among those downregulated, indicating that chronic hypoxia induced pulmonary hypertension, decreased pulmonary angiogenesis, and induced pulmonary cell remodeling.

Expressions of toll-like receptors (TLR) genes TLR2, TLR4, and nitric oxide synthase 1, 2, 3 genes were altered less than 2-fold.

Validated gene expression related to pulmonary vascularization and alveolarization. We performed real-time PCR and Western blotting analysis to validate CXCL12, jagged2, Hif $2 \alpha$, and c-Kit expression in the neonatal rat lungs exposed to hypoxia for 0,3 , and $10 \mathrm{~d}$. CXCL12 gene expression was increased by 1.8 -fold after 10-d hypoxia exposure compared with normoxia exposure (Fig. 4A). Jagged 2 gene expression was increased by 1.8 and 2.2-fold after 3- and 10-d hypoxia exposure compared with normoxia exposure (Fig. 4B). Increased CXCL12 and Jagged 2 gene expression after hypoxia exposure was negatively correlated with the development of the neonatal lungs. Western blotting showed Hif- $2 \alpha$ was decreased by 2 -fold after $10 \mathrm{~d}$ hypoxia exposure (Fig. $4 C$ and $E$ ) and c-Kit 
Table 3. Upregulated genes in the newborn rat lungs after 10-d chronic hypoxic exposure

\begin{tabular}{|c|c|c|c|c|}
\hline Gene & Common number & Accession change & Fold value & $p$ \\
\hline \multicolumn{5}{|l|}{ Metabolism } \\
\hline Chitinase, acidic & Chia & AI639227 & 9.1 & 0.005 \\
\hline Solute carrier family 1 & Slc1a6 & NM_032065 & 7.9 & 0.000 \\
\hline Rhesus blood group-associated A glycoprotein & Rhag & NM_023022 & 7.6 & 0.047 \\
\hline Solute carrier family 4 , member 1 & Slc4a1 & BE113640 & 6.4 & 0.001 \\
\hline Intersectin 1 & Itsn & BF406692 & 4.3 & 0.001 \\
\hline Solute carrier family 4 , member 1 & Slc4a1 & AY030082 & 3.8 & 0.012 \\
\hline Transferrin receptor & Tfrc & BF417032 & 3.8 & 0.003 \\
\hline Aminolevulinic acid synthase 2 & Alas2 & NM_013197 & 3.8 & 0.000 \\
\hline Peptidoglycan recognition protein & Pglyrp & NM_053373 & 3.5 & 0.003 \\
\hline Secretoglobin, family $3 \mathrm{~A}$, member 1 & Scgb3a1 & AI011836 & 3.3 & 0.010 \\
\hline Alpha-2u globulin PGCL4 & Obp3 & J00738 & 3.2 & 0.036 \\
\hline Organic cation transporter OCTN1 & Octn1 & NM_022270 & 3.0 & 0.002 \\
\hline Arachidonate 12-lipoxygenase & Alox 12 & NM_031010 & 3.0 & 0.001 \\
\hline Cytosolic cysteine dioxygenase 1 & Cdo1 & NM_052809 & 2.8 & 0.014 \\
\hline$S$-adenosylmethionine decarboxylase 1 & Amd1 & NM_031011 & 2.8 & 0.031 \\
\hline Aldose reductase-like protein & LOC 286921 & AI 233740 & 2.7 & 0.000 \\
\hline Transferrin & $\mathrm{Tf}$ & AA945178 & 2.6 & 0.003 \\
\hline Metallothionein & Mt1a & AF411318 & 2.5 & 0.016 \\
\hline Monocarboxylate transporter & Mct3 & NM_030834 & 2.5 & 0.001 \\
\hline Coagulation factor XIIIa & F13a & BM 388525 & 2.4 & 0.000 \\
\hline Adenylate kinase 4 & Ak4 & AA891949 & 2.4 & 0.034 \\
\hline RNA binding motif protein 14 & Rbm14 & BF284573 & 2.4 & 0.009 \\
\hline Lipase, hormone sensitive & Lipe & NM_012859 & 2.3 & 0.004 \\
\hline Chitinase 3-like 1 (cartilage glycoprotein-39) & Chi311 & AA945643 & 2.3 & 0.003 \\
\hline Apobec- 1 complementation factor & Acf & NM_133400 & 2.2 & 0.031 \\
\hline Solute carrier family 28, member 2 & Slc28a2 & NM_031664 & 2.2 & 0.000 \\
\hline Peptidyl arginine deiminase, type 4 & Pdi4 & AB008803 & 2.2 & 0.045 \\
\hline Inhibitor of DNA binding 4 & $\mathrm{Idb} 4$ & AI412150 & 2.2 & 0.006 \\
\hline UDP-glucuronosyltransferase & LOC286989 & U27518 & 2.1 & 0.004 \\
\hline Fatty acid elongase 2 & rELO2 & BF396857 & 2.1 & 0.003 \\
\hline Asparagine synthetase & Asns & U07202 & 2.0 & 0.026 \\
\hline \multicolumn{5}{|l|}{ Extracellular matrix } \\
\hline Matrix metalloproteinase 9 & Mmp9 & NM_031055 & 3.6 & 0.022 \\
\hline \multicolumn{5}{|l|}{ Skeletal/cell adhesion } \\
\hline Lectin, galactose binding, soluble 5 & Lgals5 & NM_012976 & 2.9 & 0.007 \\
\hline Embigin & Emb & NM_053719 & 2.7 & 0.020 \\
\hline Troponin $\mathrm{T} 2$ & Tnnt2 & NM_012676 & 2.4 & 0.006 \\
\hline \multicolumn{5}{|l|}{ Growth } \\
\hline Erythroid differentiation gene 1 & Edag1 & NM_133294 & 3.8 & 0.001 \\
\hline Resistin-like alpha & Retnla & NM_053333 & 3.5 & 0.013 \\
\hline Follistatin & Fst & NM_012561 & 3.4 & 0.045 \\
\hline Neuritin & Nrn & NM_053346 & 3.4 & 0.002 \\
\hline Schlafen 4 & Slfn4 & NM_053687 & 3.2 & 0.002 \\
\hline Neurturin & Nrtn & AI598581 & 3.0 & 0.025 \\
\hline Plasticity related gene 1 & Prg1 & AW526088 & 2.7 & 0.010 \\
\hline Cell division cycle 25B & $\mathrm{Cdc} 25 \mathrm{~b}$ & NM_133572 & 2.3 & 0.001 \\
\hline EGL nine homolog 3 (C. elegans) & $E g \ln 3$ & NM_019371 & 2.0 & 0.010 \\
\hline \multicolumn{5}{|l|}{ Inflammation } \\
\hline Tumor necrosis factor receptor $1 \mathrm{~b}$ & Tnfrsf1b & BM390522 & 4.5 & 0.006 \\
\hline S100 calcium-binding protein A8 & S100a8 & NM_053822 & 4.2 & 0.005 \\
\hline S100 calcium-binding protein A9 & S100a9 & NM_053587 & 3.7 & 0.005 \\
\hline Interferon-gamma inducible gene, Puma-g & Pumag & BI296811 & 2.9 & 0.010 \\
\hline Cathelicidin & CRAMP & AA998531 & 2.6 & 0.034 \\
\hline Chemokine (C-X-C motif) ligand 12 & Cxcl12 & BF283398 & 2.1 & 0.001 \\
\hline Interleukin 1 receptor, type II & $\mathrm{I} 11 \mathrm{r} 2$ & NM_053953 & 2.1 & 0.026 \\
\hline \multicolumn{5}{|l|}{ Signaling } \\
\hline Regulated endocrine-specific protein 18 & Resp18 & NM_019278 & 16.7 & 0.004 \\
\hline Delta-like homolog (Drosophila) & Dlk1 & NM_053744 & 5.5 & 0.046 \\
\hline CD52 antigen & Cd52 & NM_053983 & 4.8 & 0.021 \\
\hline Neurotrophic tyrosine kinase, receptor, type 2 & Ntrk2 & M55292 & 4.7 & 0.023 \\
\hline Arg/Abl-interacting protein ArgBP2 & Argbp2 & NM_053770 & 3 & 0.014 \\
\hline WNT1 inducible signaling pathway protein 2 & Wisp2 & NM_031590 & 2.7 & 0.027 \\
\hline Purinergic receptor $\mathrm{P} 2 \mathrm{Y}$, G-protein coupled 2 & P2ry2 & NM_017255 & 2.4 & 0.024 \\
\hline Calcium binding protein 1 & Cabp1 & AJ315761 & 2.3 & 0.012 \\
\hline Arginine vasopressin receptor $1 \mathrm{~A}$ & Avpr1a & NM_053019 & 2.3 & 0.026 \\
\hline Jagged 2 & Jag2 & BI274746 & 2.1 & 0.013 \\
\hline \multicolumn{5}{|l|}{ Defense response } \\
\hline Heat shock $70 \mathrm{kD}$ protein $1 \mathrm{~A}$ & Hspa1a & BI278231 & 2.5 & 0.040 \\
\hline Synuclein, alpha & Snca & NM_019169 & 2.3 & 0.025 \\
\hline Peroxiredoxin 2 & $\operatorname{Prdx} 2$ & NM_017169 & 2.1 & 0.013 \\
\hline \multicolumn{5}{|l|}{ Transcription } \\
\hline Activating transcription factor 3 & Atf3 & NM_012912 & 2.3 & 0.001 \\
\hline DNA-damage inducible transcript 3 & Ddit3 & NM_024134 & 2.2 & 0.029 \\
\hline
\end{tabular}

Total RNA from the neonatal rat lungs exposed to normoxia or hypoxia for $10 \mathrm{~d}$ was used for gene expression analysis using rat Affymatrix gene chips. Triplicate samples were analyzed from each group. $p$-value was calculated by $t$ test. 
Table 4. Downregulated genes in the newborn rat lungs after 10-d chronic hypoxic exposure

\begin{tabular}{|c|c|c|c|c|}
\hline Gene & Common number & Accession change & Fold value & $p$ \\
\hline \multicolumn{5}{|l|}{ Metabolism } \\
\hline Aldehyde dehydrogenase family 1 & Aldh1a4 & M23995 & -9.6 & 0.035 \\
\hline NAD-dependent 15 -hydroxyprostaglandin dehydrogenase & Hpgd & AA848820 & -5.1 & 0.004 \\
\hline 3-alpha-hydroxysteroid dehydrogenase & LOC191574 & M61937 & -4.0 & 0.009 \\
\hline Eosinophil cationic protein & Loc192264 & D88586 & -3.4 & 0.002 \\
\hline Dopa decarboxylase & Ddc & BI296559 & -3.4 & 0.001 \\
\hline Solute carrier family 28 & Slc28a3 & NM_080908 & -3.3 & 0.009 \\
\hline P-glycoprotein/multidrug resistance 1 & Pgy1 & AY082609 & -3.2 & 0.014 \\
\hline Rab3B protein & Rab3b & NM_031091 & -3.0 & 0.012 \\
\hline ATP-binding cassette, sub-family B (MDR/TAP) & Abcb1a & $\mathrm{AF} 257746$ & -2.7 & 0.012 \\
\hline Monoamine oxidase B & Maob & NM_013198 & -2.4 & 0.000 \\
\hline Flavin containing monooxygenase 4 & Fmo4 & BI293319 & -2.3 & 0.009 \\
\hline Pyruvate dehydrogenase kinase 2 & Pdk2 & AF237719 & -2.1 & 0.005 \\
\hline 3-hydroxy-3-methylglutaryl-coenzyme A synthase 2 & Hmgcs2 & M33648 & -2.1 & 0.027 \\
\hline Casein kinase II, alpha 1 polypeptide & Csnk2a1 & BF555171 & -2.1 & 0.003 \\
\hline Chloride channel 7 & Clcn7 & NM_031568 & -2.1 & 0.049 \\
\hline Acyl-coenzyme A oxidase 2, branched chain & Acox 2 & X95189 & -2.1 & 0.008 \\
\hline Sulfatase FP & LOC171396 & NM_134378 & -2.0 & 0.003 \\
\hline \multicolumn{5}{|l|}{ Extracellular matrix } \\
\hline Lumican & Lum & NM_031050 & -2.4 & 0.004 \\
\hline Vitronectin & Vtn & NM_019156 & -2.3 & 0.016 \\
\hline Bone morphogenetic protein 1 (procollagen C-proetinase) & Bmp1 & АВ012139 & -2.1 & 0.018 \\
\hline Matrix metalloproteinase 14, membrane-inserted & Mmp14 & X83537 & -2.1 & 0.004 \\
\hline Procollagen, type XII, alpha 1 & Col12a1 & U57361 & -2.1 & 0.022 \\
\hline Actin alpha cardiac 1 & Actc1 & BF525047 & -2.1 & 0.016 \\
\hline \multicolumn{5}{|l|}{ Skeletal/cell adhesion } \\
\hline Claudin 11 & Cldn11 & NM_053457 & -3.2 & 0.018 \\
\hline Opioid-binding protein/cell adhesion molecule-like & Opcml & NM_053848 & -2.3 & 0.011 \\
\hline Nuclear pore membrane glycoprotein 210 & Pom 210 & NM_053322 & -2.3 & 0.002 \\
\hline CD38 antigen & $\mathrm{Cd} 38$ & D30795 & -2.1 & 0.002 \\
\hline \multicolumn{5}{|l|}{ Growth } \\
\hline Bone specific CMF608 & LOC310448 & BF543355 & -2.7 & 0.004 \\
\hline Niban protein & Niban & NM_022242 & -2.3 & 0.016 \\
\hline Protocadherin alpha 13 & Pcdha13 & BG663483 & -2.1 & 0.000 \\
\hline Insulin-like growth factor-binding protein 5 & Igfbp5 & BF399783 & -2.0 & 0.006 \\
\hline Cyclin dependent kinase inhibitor $2 \mathrm{C}$ & Cdkn2c & NM_131902 & -2.0 & 0.010 \\
\hline \multicolumn{5}{|l|}{ Inflammation } \\
\hline Interleukin 1 alpha & Il1a & AJ245643 & -2.2 & 0.008 \\
\hline T-cell receptor gamma chain & Tcrg & Z27087 & -2.1 & 0.003 \\
\hline T-cell receptor beta chain & Tcrb & AW919577 & -2.0 & 0.010 \\
\hline \multicolumn{5}{|l|}{ Signaling } \\
\hline Vasoactive intestinal peptide receptor 1 & Vipr1 & NM_012685 & -5.1 & 0.006 \\
\hline Bradykinin receptor $\mathrm{B} 2$ & Bdkrb2 & BF408558 & -4.1 & 0.007 \\
\hline G protein-coupled receptor 105 & Gpr105 & U76206 & -3.8 & 0.001 \\
\hline Carcinoembryonic antigen-related cell adhesion molecule 1 & Ceacam 1 & NM_031755 & -3.7 & 0.018 \\
\hline Natriuretic peptide receptor 3 & Npr3 & AI574783 & -3.4 & 0.038 \\
\hline c-kit receptor tyrosine kinase & Kit & NM_022264 & -3.0 & 0.003 \\
\hline Neurotensin receptor 2 & $\mathrm{Ntsr} 2$ & U18772 & -3.0 & 0.002 \\
\hline Adrenomedullin & Adm & NM_012715 & -2.6 & 0.013 \\
\hline Glial cell line-derived neurotrophic factor family receptor alpha 2 & Gfra2 & BE114004 & -2.5 & 0.021 \\
\hline Regulator of G-protein signaling 7 & Rgs7 & NM_019343 & -2.5 & 0.000 \\
\hline Thyroid stimulating hormone, receptor & Tshr & NM_012888 & -2.5 & 0.004 \\
\hline Adrenomedullin receptor & Admr & NM_053302 & -2.4 & 0.007 \\
\hline Phosphatidylinositol 3-kinase, catalytic, alpha polypeptide & Pik3ca & AA964375 & -2.3 & 0.002 \\
\hline Angiopoietin-like 2 & Angpt12 & NM_133569 & -2.1 & 0.011 \\
\hline Ephrin A1 & Efnal & NM_053599 & -2.1 & 0.005 \\
\hline Calcitonin receptor-like & Calcrl & NM_012717 & -2.0 & 0.049 \\
\hline RAS guanyl releasing protein 1 & Rasgrp1 & AF081196 & -2.0 & 0.013 \\
\hline Endothelial PAS domain protein 1 & Epas1 & NM_023090 & -2.0 & 0.014 \\
\hline \multicolumn{5}{|l|}{ Transcription } \\
\hline Period 1 & Per1 & BI279017 & -4.5 & 0.015 \\
\hline Zinc finger protein $354 \mathrm{C}$ & $\mathrm{Znf} 354 \mathrm{c}$ & NM_023988 & -2.2 & 0.011 \\
\hline Transcription factor E2a & Tcfe $2 \mathrm{a}$ & NM_133524 & -2.1 & 0.038 \\
\hline
\end{tabular}

Total RNA from the neonatal rat lungs exposed to normoxia or hypoxia for $10 \mathrm{~d}$ was used for gene expression analysis using rat Affymatrix gene chips. Triplicate samples were analyzed from each group. $p$-value was calculated by $t$ test. 


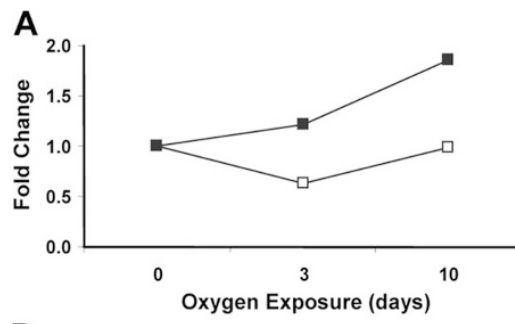

D

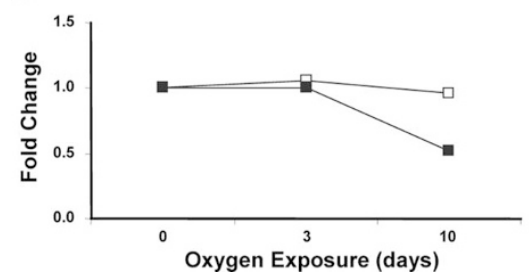

B

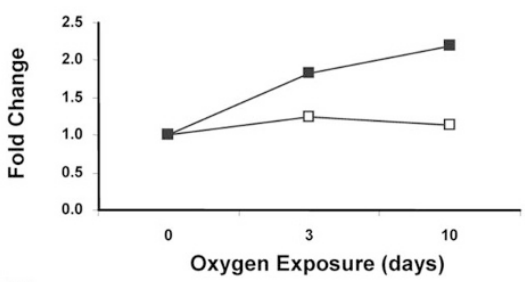

E

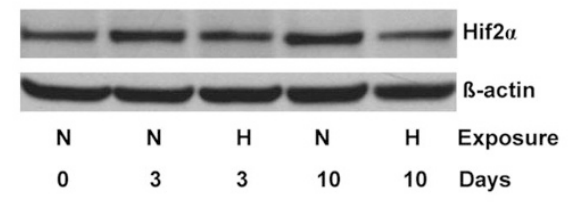

C

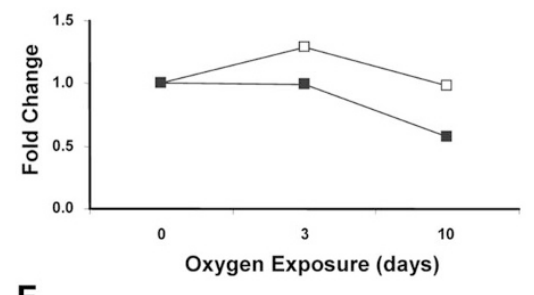

F

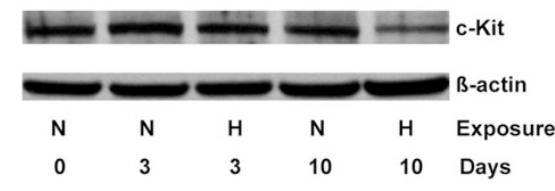

Figure 4. Validation of gene expression by quantitative PCR and Western blotting analysis. (A) and (B), CXCL12 and Jagged 2 gene expression in the neonatal rat lungs exposed to either normoxia or hypoxia for 0,3 , and $10 \mathrm{~d}$ was performed by quantitative real-time PCR. Open square: normoxia; closed square: hypoxia. $(C)$ and $(D)$, Hif- $2 \alpha$ and C-Kit protein expression in the neonatal rat lungs exposed to either normoxia or hypoxia for 0,3 , and $10 \mathrm{~d}$ was analyzed by Western blotting. (E), Western blotting analysis of Hif2 $\alpha$ expression; N: normoxia; H: hypoxia. $(F)$, Western blotting analysis of c-Kit expression; N: normoxia; H: hypoxia; Open squares: normoxia; closed squares: hypoxia.

was decreased by 2-fold after 10-d hypoxia exposure (Fig. 4D and $F$ ), which were consistent with the gene expression data from Affymatrix DNA microarray. The increased expression of CXCL12 and jagged 2 and decreased expression of Hif- $2 \alpha$ and c-Kit were correlated with the reduction of alveolar formation during chronic hypoxia exposure.

\section{DISCUSSION}

In this study, we analyzed differential gene expression and distal lung development after $\mathrm{FIO}_{2}$ of 0.12 exposure from day 4 to day 14. Hypoxia in the dose and duration used impaired alveolar formation and reduced body weight and lung wet weight during the secondary septation period. Hypoxic exposure increased gene expression of Notch signaling such as jagged 2, and antioxidants such as heat shock protein 70 and peroxiredoxin 2; decreased gene expression of ephrin A1 and Hif- $2 \alpha$ that are implicated in vascularization. Real-time PCR and Western blotting confirmed that downregulation of Hif- $2 \alpha$ and c-Kit, and upregulation of CXCL12 and jagged 2 are correlated with impairment of alveolar formation after chronic hypoxia in the neonatal rat lungs.

Chronic hypoxia can impair pulmonary vascularization and alveolar formation in neonatal rats and humans $(14,15)$. Alveolar hypoxia in this model reduced pulmonary vessel density, RAC and increased mean Lm. The pups demonstrated fewer and larger alveoli. In addition, it significantly impeded pulmonary vascularization as assessed by decreased vessel density. Our findings suggest that there was diminished secondary septation. Lung development in the first 2 wks of life is largely dependent on secondary septation $(2,16,17)$. However, it is unclear how hypoxia affects the secondary septation. To help clarify this process, we performed DNA array analysis and probed more than 2800 genes. Among those significantly differentially expressed genes, approximately half of those genes were unknown. Chronic hypoxia in the neonatal rat lung significantly upregulated and downregulated genes related to pathogenesis of pulmonary hypertension and vascularization.
For example, jagged 2, a ligand of Notch receptors, was significantly increased during hypoxia exposure, suggesting that Notch signaling pathway may be dysregulated in the newborn rats exposed to chronic hypoxia. The Notch signaling pathway plays an important role in the regulation of arterialvenous differentiation. Jagged 2 is expressed in endothelial cells in developing lungs $(18,19)$. The Notch ligand negatively regulated vascularization during development and interruption of Notch signaling increases number of lung buds and branching morphogenesis, although the exact role of Jagged 2 in the developing lungs has not been clearly defined (20-22). CXCL12 (also known as stromal cell-derived factor-1) and its receptor, CXCR4, play important roles in ischemic tissue repair, progenitor cell mobilization, and neovascularization during hypoxia exposure $(23,24)$. We found that CXCL12 was significantly elevated in the hypoxia-exposed lungs, which indicated that CXCL12 might participate in pulmonary remodeling after hypoxia. The downregulation of c-Kit, a transmembrane tyrosine kinase receptor for stem-cell factor, may reflect the decreasing mobilization of c-Kit positive cells from the bone marrow to lung after prolonged hypoxia. Recent data have suggested that c-kit positive cells could differentiate into endothelial cells and could be involved in the hypoxia-induced remodeled pulmonary artery vessel wall (25).

The finding of decreased Hif $2 \alpha$ expression was unexpected, but it has been reported that chronic hypoxia could reduce gene expression that Hif regulates (26). Chronic hypoxia also altered gene expression in inflammation, oxidative stress, and cell survival pathways, suggesting that multiple factors and pathways are involved in postnatal lung remodeling during chronic hypoxia. Genes participating in the regulation of TLR were altered by $<2$-fold. This finding was of importance, as relative TLR4 deficiency has been shown to induce susceptibility to a different model of lung injury (27). We used a conservative cutoff of 2-fold gene alteration as a criterion in the gene expression analysis and examined one relatively late time point, hypoxia for $10 \mathrm{~d}$. Additional gene 
upregulation or downregulation might have been found if we have looked at the early time points such as hypoxia for $3 \mathrm{~d}$.

Several features of the model used in these experiments need to be discussed. Animals were exposed to $\mathrm{FIO}_{2}=0.12$ beginning on day 4 and continuing to day 14 of life. We chose this model after pilot work with exposure to $\mathrm{FIO}_{2}=0.10$ resulted in unacceptably high mortality at and beyond $7 \mathrm{~d}$ of exposure. Also, infants born at an altitude at which the $\mathrm{FIO}_{2}$ is approximately 0.12 (28) demonstrate impaired gas exchange (10). With $\mathrm{FIO}_{2}=0.12$ there were no unplanned deaths of the exposure pups. We waited $4 \mathrm{~d}$ after birth to initiate hypoxic exposure to mimic the contemporary clinical course of BPD. There is often a "honeymoon" of up to one to 2 wks during which supplemental $\mathrm{FIO}_{2}$ needs and ventilatory support are minimal. Our findings, obtained after a short waiting period, demonstrate that sublethal alveolar hypoxia still profoundly disrupts pulmonary development, and that histologically, $3 \mathrm{~d}$ exposure is insufficient to produce these changes. There are obvious limitations in comparing carefully controlled administration of $\mathrm{O}_{2}$ and resultant perturbations in lung development conducted on small mammal species to human studies, but this brief period of normoxia followed by $10 \mathrm{~d}$ breathing $\mathrm{FIO}_{2}$ of 0.12 was associated with histopathological and transcriptive changes. We cannot speculate as to whether hypoxia beginning at day 0 , or alternatively, waiting until day 7 would have exacerbated or minimized these findings.

There are several unique features to the study. To our knowledge, ours is the first report using the rat-specific wide array gene chip analysis for identifying rat lung gene expression profiles following alveolar hypoxic exposure. Several previously uncharacterized gene expression patterns were identified and potentially offer important therapeutic targets. We sought to identify correlations between alveolar and microvascular abnormal development and up- or downregulation of key genes in the rat lung known or suspected to be associated with vascular/airway development. Other methodological factors of note included the use of a concurrent limited feeding group to minimize, but likely not eliminate, the effect of reduced nutritional intake by the rat pups during their hypoxic exposure. Use of a pair fed normoxia comparison group increases the likelihood that the pulmonary findings in the chronic hypoxia group were caused directly by the effects of alveolar hypoxia and not by secondary effects of nutrient intake.

In summary, we showed that chronic hypoxia interrupted lung development, likely inducing permanent structural alterations. The corresponding altered gene expression pattern indicates that multiple pathways were involved.

\section{REFERENCES}

1. Burri PH 1997 Structural aspects of pre- and postnatal development and growth of the lung. In: McDonald JA (ed) Growth and Development of the Lung. Marcel Dekker, Inc., New York, pp 1-35

2. Burri PH 1984 Fetal and postnatal development of the lung. Annu Rev Physiol 46:617-628
3. Risau W 1991 Vasculogenesis, angiogenesis and endothelial cell differentiation during embryonic development. In: Feinberg RN, Sherer GK, Auerbach R (eds) The Development of the Vascular System. Karger, Biomed Basel 14: pp 58-68

4. Gale NW, Yancopoulos GD 1999 Growth factors acting via endothelial cell-specific receptor tyrosine kinases: VEGFs, angiopoietins, and ephrins in vascular development. Genes Dev 13:1055-1066

5. DeMello DE, Reid LM 1991 Pre- and postnatal development of the pulmonary circulation. In: Chernick V, Mellins RB (eds) Basic Mechanisms of Pediatric Respiratory Disease: Cellular and Integrative. Decker, Philadelphia, pp 6-54

6. Jakkula M, Le Cras TD, Gebb S, Hirth KP, Tuder RM, Voelkel NF, Abman SH 2000 Inhibition of angiogenesis decreases alveolarization in the developing rat lung. Am J Physiol Lung Cell Mol Physiol 279:L600-L607

7. Stenmark KR, Abman SH 2005 Lung vascular development: implications for the pathogenesis of bronchopulmonary dysplasia. Annu Rev Physiol 67:623661

8. Semenza GL 2005 Pulmonary vascular responses to chronic hypoxia mediated by hypoxia-inducible factor 1. Proc Am Thorac Soc 2:68-70

9. Thibeault DW, Truog WE, Ekekezie I 2003 Acinar arterial changes with chronic lung disease of prematurity in the surfactant era. Pediatr Pulmonol 36:482489

10. Niermeyer S, Yang P, Shanmina, Drolkar, Zhuang J, Moore LG 1995 Arterial oxygen saturation in Tibetan and Han infants born in Lhasa, Tibet. N Eng J Med 333:1248-1252

11. Cooney TP, Thurlbeck WM 1982 The radial alveolar count method of Emery and Mithal: a reappraisal 1-postnatal lung growth. Thorax 37:580-583

12. Emery JL, Mithal A 1960 The number of alveoli in the terminal respiratory unit of man during intrauterine life and childhood. Arch Dis Child 35:544-547

13. Dunnill MS 1962 Quantitative methods in the study of pulmonary pathology. Thorax $17: 320-328$

14. Deruelle P, Balasubramaniam V, Kunig AM, Seedorf GJ, Markham NE, Abman SH 2006 BAY 41-2272, a direct activator of soluble guanylate cyclase, reduces right ventricular hypertrophy and prevents pulmonary vascular remodeling during chronic hypoxia in neonatal rats. Biol Neonate 90:135-144

15. Chess PR, D'Angio CT, Pryhuber GS, Maniscalco WM 2006 Pathogenesis of bronchopulmonary dysplasia. Semin Perinatol 30:171-178

16. Thibeault DW, Mabry SM, Norberg M, Truog WE, Ekekezie II 2004 Lung microvascular adaptation in infants with chronic lung disease. Biol Neonate $85: 273-282$

17. Olsen SL, Thibeault DW, Mabry SM, Norberg M, Truog WE 2002 Platelet endothelial cell adhesion molecule- 1 and capillary loading in premature infants with and without chronic lung disease. Pediatr Pulmonol 33:255-262

18. Taichman DB, Loomes KM, Schachtner SK, Guttentag S, Vu C, Williams P, Oakey RJ, Baldwin HS 2002 Notch1 and Jagged1 expression by the developing pulmonary vasculature. Dev Dyn 225:166-175

19. Iso T, Hamamori Y, Kedes L 2003 Notch signaling in vascular development Arterioscler Thromb Vasc Biol 23:543-553

20. Suchting S, Freitas C, le Noble F, Benedito R, Breant C, Duarte A, Eichmann A 2007 The Notch ligand Delta-like 4 negatively regulates endothelial tip cell formation and vessel branching. Proc Natl Acad Sci USA 104:3225-3230

21. Lobov IB, Renard RA, Papadopoulos N, Gale NW, Thurston G, Yancopoulos GD, Wiegand SJ 2007 Delta-like ligand 4 (Dll4) is induced by VEGF as a negative regulator of angiogenic sprouting. Proc Natl Acad Sci USA 104:32193224

22. Kong Y, Glickman J, Subramaniam M, Shahsafaei A, Allamneni KP, Aster JC, Sklar J, Sunday ME 2004 Functional diversity of notch family genes in fetal lung development. Am J Physiol Lung Cell Mol Physiol 286:L1075-L1083

23. Ceradini DJ, Kulkarni AR, Callaghan MJ, Tepper OM, Bastidas N, Kleinman ME, Capla JM, Galiano RD, Levine JP, Gurtner GC 2004 Progenitor cell trafficking is regulated by hypoxic gradients through HIF-1 induction of SDF-1. Nat Med 10:858-864

24. Lima e Silva R, Shen J, Hackett SF, Kachi S, Akiyama H, Kiuchi K, Yokoi K, Hatara MC, Lauer T, Aslam S, Gong YY, Xiao WH, Khu NH, Thut C, Campochiaro PA 2007 The SDF-1/CXCR4 ligand/receptor pair is an important contributor to several types of ocular neovascularization. FASEB J 21:3219-3230

25. Davie NJ, Crossno JT Jr, Frid MG, Hofmeister SE, Reeves JT, Hyde DM, Carpenter TC, Brunetti JA, McNiece IK, Stenmark KR 2004 Hypoxia-induced pulmonary artery adventitial remodeling and neovascularization: contribution of progenitor cells. Am J Physiol Lung Cell Mol Physiol 286:L668-L678

26. Grover TR, Asikainen TM, Kinsella JP, Abman SH, White CW 2007 Hypoxiainducible factors HIF- $1 \alpha$ and HIF- $2 \alpha$ are decreased in an experimental model of severe respiratory distress syndrome in preterm lambs. Am J Physiol Lung Cell Mol Physiol 292:L1345-L1351

27. Zhang X, Shan PBlob, Qureshi S, Homer R, Medzhitov R, Noble PW, Lee PJ 2005 Cutting edge: TLR4 deficiency confers susceptibility to lethal oxidant lung injury. J Immunol 175:4834-4838

28. Erzurum SC, Ghosh S, Janocha AJ, Xu W, Bauer S, Bryan NS, Tejero J, Hemann C, Hille R, Stuehr DJ, Feelisch M, Beall CM 2007 Higher blood flow and circulating NO products offset high-altitude hypoxia among Tibetans. Proc Natl Acad Sci USA 104:17593-17598 